\title{
Price Stickiness under Stochastic Demand
}

\author{
Sheng-Yeh, $\mathrm{Wu}^{1}$ and Guan-Ru, Chen ${ }^{2}$
}

\begin{abstract}
This study develops a two-period model in which the manufacturer determines a price floor and sets production output prior to resolution of uncertainty. The closer the distance between the minimum price and the high-demand-state price, the higher the degree of price rigidity. Solving for the minimum resale price and production output, the model indicates that asymmetric price transmission could be a characteristic of competitive markets. The retail price in a highly concentrated retail market might be lower than that in a retail market with fierce competition. The relationship between price adjustments and the market competition suggests that the reason underlying price rigidity should be considered while formulating the antitrust and monetary policies.
\end{abstract}

JEL classification numbers: D12, L11

Keywords: Price Rigidity, Price Floor, Uncertainty

\section{Introduction}

Although classical economics predicts continuous and full adjustment of prices in response to continuous changes in supply and demand conditions, price rigidity has been documented for a variety of markets (Carlton, 1986; Kashyap, 1995; Bils et al., 2003; Klenow and Kryvtsov, 2008; Nakamura and Steinsson, 2008). In theoretic models, the market-clearing prices are inevitably volatile if the manufacturers' output is determined before the realization of demand uncertainty. Likewise, models that treat retail prices as fixed variables cannot explain why price rigidity varies across products, as described by previous studies. Caplin (1993) describes it as unfortunate "that so little attention has been given to characterizing the circumstances that give rise to high and low levels of nominal price inertia," while the factors influencing firms' price changes are critically important to understanding the workings of a market economy and the consequences of public policy (Blinder et al., 1998). Carlton (1986) found that steel, chemical, and cement have a higher degree of price rigidity than household appliances, plywood, and nonferrous metal. Bils et al. (2003) found that prices of newspapers, men's haircuts and taxi fares change less than once every two years, while prices of gasoline, tomatoes and plane tickets change more than once a month on average, suggesting that the frequency of price changes varies dramatically across products. Conlisk et al. (1984), Caucutt et al. (1994, 1999), and Tirole (1988) found that durable products have a relatively high price rigidity across industrial product classes, indicating that the salvage value of merchandise plays a role in price stickiness. Since 1970, an often-noted concern in congressional hearings and commissions is that retail prices respond asymmetrically to exogenous changes (Mathews et al., 1999). The conventional industrial organization (IO) wisdom suggests that prices in less competitive markets display more downward stickiness than prices in highly competitive markets (the administered-price hypothesis, Mean, 1935). Likewise, Carlton (1986) also reported that the level of

\footnotetext{
1 Finance Department, I-Shou University, Taiwan.

2 International Finance Department, I-Shou University, Taiwan.
}

Article Info: Received: July 29, $2020 \quad$ Published online: August 25, 2020 
market concentration is strongly correlated with price stickiness. However, other studies used more aggregate data to examine the speed of price adjustment, yielding conflicting results. Domberger (1979, 1983) and Weaver (1989) found that prices in more concentrated industries adjusted more quickly to changes in costs or demand, Kraft (1995) further indicated that prices are more flexible in periods of high demand than in times of recession. Domowitz et al. (1986) found a significant positive relationship between the speed of price adjustment and market concentration in producer goods and consumer goods industries. Caucutt et al. (1999) found that the sizes of price changes in consumer goods are positively related to market concentration, while those of price changes in producer goods are negatively related to market concentration. This suggests that the effects of market concentration on prices differ depending on whether the goods are for final consumption or are intermediate inputs. Weaver (1989) indicated that the presence of output and price control in a concentrated market of imperfectly competitive firms implies coordination and this may suggest that prices adjust efficiently to maintain desired levels of profit. Powers and Powers (2001) studied retail markets and concluded that markets that are more concentrated experience larger price changes. Peltzman (2000) argues that asymmetric price transmission may be a characteristic of competitive markets, and its presence does not automatically imply market power. Weber and Anders (2007) showed that large retailers change prices more frequently than small companies do. Holzer and Bittmann (2019) found that private label products are more rigid than national brands, since national brands hold a stronger market power. In summary, the existing literature on the association between market concentration and price inertia is mixed.

The remainder of this study aims to investigate the relation between market power and price rigidity. As market competition intensifies, do market price become more stable or more volatile? We establish an economic model to yield numerical analysis to answer this question in supporting of empirical literature. The remainder of this study is organized as follows. Section 2 analyzes variations in price rigidity by constructing a model with a monopoly manufacturer. Section 3 uses a numerical analysis to depict the extent price adjustment under various parameters. Section 4 explains the managerial implications of price rigidity model and concludes.

\section{The Model}

In the basic setting, the manufacturer sells her merchandise directly to consumers instead of selling through retailers. For a two-period model under demand uncertainty, the manufacturer must determine the production output and price floor before the resolution of demand. The details can be summarized in the following assumptions.

Assumption 1: There is a pre-season $(t=1)$ and a selling season $(t=2)$. A risk-neutral manufacturer produces the merchandise at $t=1$, with production cost as follows:

$$
T C=\left(f_{0}+f_{1} Q\right) Q
$$

where $f_{0}, f_{1}>0$ are constants, and $Q$ denotes production output.

Assumption 2: At $t=1$, the current demand is given by:

$$
Q=a X-b P
$$

where $a, b>0$ are constants, $P$ is the market price, $X$ is the demand uncertainty that realizes at $t=2$, and has a binominal probability distribution as follows:

$$
X=\left\{\begin{array}{c}
X_{H}=X e^{v \sqrt{t}}, \text { with probability }=\alpha \\
X_{L}=X e^{-v \sqrt{t}}, \text { with probability }=1-\alpha
\end{array}\right.
$$

The probability $\alpha>0$ can be given exogenously or determined endogenously. The latter is the risk-neutral probability (Cox et al., 1979), and can be written as: 


$$
\alpha=\frac{e^{r t}-e^{-v \sqrt{t}}}{e^{v \sqrt{t}}-e^{-v \sqrt{t}}}
$$

where $r>0$ denotes the discount rate, $v>0$ denotes the volatility of demand shocks, $t>0$ denotes the time interval between two periods, while $e^{v \sqrt{t}}$ and $e^{-v \sqrt{t}}$ are the percentages of upward and downward movements, respectively. The risk-neutral probability has the advantage of being independent of subjective beliefs regarding the occurrence of the possible states, and it ensures that the expected growth rate of demand equals the discount rate $r$, which can be written as:

$$
e^{r}=\alpha \cdot e^{v \sqrt{t}}+(1-\alpha) e^{-v \sqrt{t}}
$$

Equation (5) shows that once the appropriate discount rate is chosen, the expected growth rate of demand will be independent of volatility and probability.

Assumption 3: Along with production output $Q$, the manufacturer determines the price floor $\underline{P}$ before the realization of market demand. If the low-demand state $\left(X=X_{L}\right)$ occurs and the market-clearing price is below the price floor at $t=2$, there are unsold quantities at the binding price floor, and the salvage value per unit is $s$.

Given Assumptions 1-3, the profit maximization problem for the manufacturer can be written as:

$\underset{Q, \underline{P}}{\operatorname{Max}} \pi_{M}=\left(-f_{0}-f_{1} Q\right) Q+m\left(\frac{a}{b} X_{H}-\frac{Q}{b}\right) Q+u \underline{P}\left(a X_{L}-b \underline{P}\right)-u s\left(Q-\left(a X_{L}-b \underline{P}\right)\right)$

s.t. $\quad \frac{a X_{H}}{b}-\frac{Q}{b} \geq \underline{P} \geq \frac{a X_{L}}{b}-\frac{Q}{b}$

where $m=\alpha e^{-r t}$, and $u=(1-\alpha) e^{-r t}$ for simplicity. If the constraint $\frac{a X_{H}}{b}-\frac{Q}{b} \geq \underline{P}$ were violated, there would be unsold goods even in the high-demand state. This would be economically unreasonable and the second-order sufficient conditions for profit maximization would not hold. If the constraint $\underline{P} \geq \frac{a X_{L}}{b}-\frac{Q}{b}$ were violated, the price floor would not bind even in the low-demand state, rendering the price floor meaningless. The solution to Equation (6) can be found by forming the Lagrangian and satisfying the Kuhn-Tucker conditions:

$$
\begin{aligned}
\mathcal{L} & =\left(-f_{0}-f_{1} Q\right) Q+m\left(\frac{a}{b} X_{H}-\frac{Q}{b}\right) Q+u \underline{P}\left(a X_{L}-b \underline{P}\right)-u s\left(Q-\left(a X_{L}-b \underline{P}\right)\right. \\
& +\lambda_{1}\left(\frac{a X_{H}}{b}-\frac{Q}{b}-\underline{P}\right)+\lambda_{2}\left(\underline{P}-\frac{a X_{L}}{b}+\frac{Q}{b}\right)
\end{aligned}
$$

The Kuhn-Tucker conditions are as follows:

$$
\begin{array}{lll}
\frac{\partial \mathcal{L}}{\partial Q} \leq 0 & Q \geq 0 & Q \frac{\partial \mathcal{L}}{\partial Q}=0 \\
\frac{\partial \mathcal{L}}{\partial \underline{P}} \leq 0 & \underline{P} \geq 0 & \underline{P} \frac{\partial \mathcal{L}}{\partial \underline{P}}=0 \\
\frac{\partial \mathcal{L}}{\partial \lambda_{1}} \leq 0 & \lambda_{1} \geq 0 & \lambda_{1} \frac{\partial \mathcal{L}}{\partial \lambda_{1}}=0 \\
\frac{\partial \mathcal{L}}{\partial \lambda_{2}} \leq 0 & \lambda_{2} \geq 0 & \lambda_{2} \frac{\partial \mathcal{L}}{\partial \lambda_{2}}=0
\end{array}
$$


Proposition 1 indicates the optimal production and price floor, both for the cases where the constraints are met with equality, as well as the cases where they are not.

Proposition 1: Given Assumptions 1-3, the manufacturer's optimal strategy consists of setting production output and price floors according to various constraints:

$$
\begin{array}{ll}
Q=\frac{a m X_{H}+b u s-b f_{0}}{2 f_{1} b+2 m}, \underline{P}=\frac{a X_{L}}{2 b}+\frac{s}{2} & \text { if } \frac{a X_{H}}{b}-\frac{Q}{b}>\underline{P}>\frac{a X_{L}}{b}-\frac{Q}{b} \\
Q=\frac{a X_{H} e^{-r t}+a u\left(X_{H}-X_{L}\right)-b f_{0}}{2 f_{1} b+2 e^{-r t}} & \text { if } \underline{P}=\frac{a X_{H}}{b}-\frac{Q}{b} \\
Q=\frac{a m X_{H}+a u X_{L}-b f_{0}}{2 f_{1} b+2 e^{-r t}} & \text { if } \underline{P}=\frac{a X_{L}}{b}-\frac{Q}{b}
\end{array}
$$

Proof: If $\frac{a X_{H}}{b}-\frac{Q}{b}>\underline{P}>\frac{a X_{L}}{b}-\frac{Q}{b}$, the Kuhn-Tucker conditions $\frac{\partial L}{\partial \lambda_{1}}, \frac{\partial L}{\partial \lambda_{2}}>0$ are naturally satisfied. Since the two constraints are not binding, one can assume $\lambda_{1}=\lambda_{2}=0$, and the first-order conditions become:

$$
\begin{aligned}
& \frac{\partial \mathcal{L}}{\partial Q}=-f_{0}-2 f_{1} Q+m\left(\frac{a X_{H}}{b}-\frac{2 Q}{b}\right)+u s=0 \\
& \frac{\partial \mathcal{L}}{\partial \underline{P}}=a u X_{u}-2 b u \underline{P}+u b s=0
\end{aligned}
$$

Solving for $Q$ and $\underline{P}$ yields:

$$
Q=\frac{a m X_{H}+b u s-b f_{0}}{2 f_{1} b+2 m}, \quad \underline{P}=\frac{a X_{L}}{2 b}+\frac{s}{2}
$$

The following second-order sufficient conditions for a maximum are automatically satisfied given $f_{1}>0$ (which is guaranteed by Assumption 1):

$\frac{\partial \mathcal{L}}{\partial Q}=-2 f_{1}-\frac{2 m}{b}<0, \frac{\partial \mathcal{L}}{\partial \underline{P}}=-2 b u<0, \frac{\partial \mathcal{L}}{\partial Q} \frac{\partial \mathcal{L}}{\partial \underline{P}}-\frac{\partial^{2} \mathcal{L}}{\partial Q \partial \underline{P}}=4\left(f_{1}+\frac{m}{b}\right)(b u)>0$

If $\underline{P}=\frac{a X_{H}}{b}-\frac{Q}{b}$, the constraint $\underline{P}=\frac{a X_{L}}{b}-\frac{Q}{b}$ cannot be binding, so we assume that $\lambda_{2}=0$. The first-order conditions become $\frac{\partial \mathcal{L}}{\partial Q}=\frac{\partial \mathcal{L}}{\partial \underline{P}}=\frac{\partial \mathcal{L}}{\partial \lambda_{1}}=0$ :

$$
\left[\begin{array}{ccc}
-2 f_{1}-\frac{2 m}{b} & 0 & \frac{1}{b} \\
0 & -2 b u \underline{P} & 1 \\
\frac{1}{b} & 1 & 0
\end{array}\right]\left[\begin{array}{l}
Q \\
\underline{P} \\
\lambda_{1}
\end{array}\right]=\left[\begin{array}{c}
f_{0}-\frac{a m X_{H}}{b}-u s \\
-a u X_{L}-u s b \\
\frac{a}{b} X_{M}
\end{array}\right]
$$

Solving the equations yields Equation (9). The second-order sufficient condition requires that the following boarded Hessian be positive: 


$$
\left|\begin{array}{ccc}
-2 f_{1}-2 m / b & 0 & 1 / b \\
0 & -2 b u \underline{P} & 1 \\
1 / b & 1 & 0
\end{array}\right|=2\left(f_{1}+m / b\right)+2 u \underline{P}
$$

That is satisfied given $f_{1}>0$. Following the same procedure, one can obtain Equation (10) under the constraint $\underline{P}=\frac{a X_{L}}{b}-\frac{Q}{b}$.

Q.E.D.

Equations (7)-(9) enable us to assess the position of the price floor relative to the prices in the high-demand and low-demand states, denoted by $P_{H}=a X_{H} / b-Q / b$ and $P_{L}=a X_{L} / b-Q / b$, respectively. A high degree of price rigidity corresponds to the price floor being near the price in the high-demand state; the prices are entirely flexible when the price floor coincides with the price in the low-demand state.

A flexible pricing model, which treats output as a single endogenous variable, can provide a point of comparison with the price rigidity model. The manufacturer's profit maximization problem can be written as follows:

$$
\operatorname{Max}_{Q} \pi_{M}=\left(-f_{0}-f_{1} Q\right) Q+m\left(\frac{a}{b} X_{H}-\frac{Q}{b}\right) Q+u\left(\frac{a}{b} X_{L}-\frac{Q}{b}\right) Q
$$

There is no unsold inventory in the flexible pricing model, so Equation (15) is not a function of salvage value. Solving for the production quantities yields:

$$
Q=\frac{a\left(m X_{H}+u X_{L}\right)}{2\left(b f_{1}+e^{-r t}\right)}-\frac{b f_{0}}{2\left(b f_{1}+e^{-r t}\right)}
$$

In the following, we use numerical analysis to illustrate the association between price rigidity and market variables. If the price floor in the price rigidity model or the low-demand state price in the flexible pricing model is lower than the salvage value $S$, they will be replaced by the salvage value. However, the lower bound on price does not limit the manufacturer's production quantities, so we do not have to add $\underline{P}>s$ or $a X_{L} / b-Q / b>s$ as constraints in the Lagrangian.

\section{Results of numerical analysis}

Fig. 1 shows the effects of salvage value on the price rigidity at the end of the selling season. As the salvage value $s$ increases, the price floor $\underline{P}$ rises until it reaches the high-demand state price. At point $A$, the price floor coincides with the high-demand state price; the market price is fixed regardless of demand fluctuations and demonstrates perfect rigidity. The value of storable goods at the end of the selling season limits the downside risk, so the producer does not have to cut price to generate sales. This result corresponds with those of Conlisk et al. (1984) and Caucutt et al. (1999), who found that durable products have relatively high price rigidity across industrial product classes. Serra and Goodwin (2003) demonstrated that price rigidity were not present on the highly perishable dairy products in Spain. 


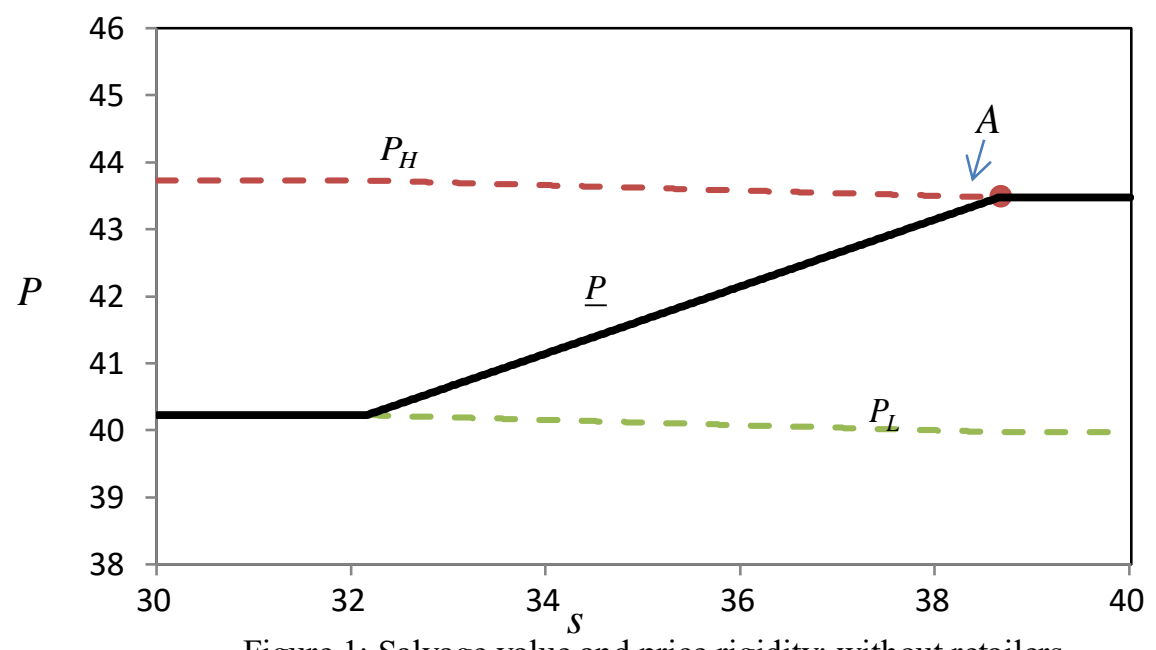

Figure 1: Salvage value and price rigidity: without retailers

Parameter values: $a=50, b=1, X=1, v=0.035, s=32, r=0.02, f_{0}=2, f_{1}=2$

Rotemberg and Saloner (1987), Taylor (2000), and Powers and Powers (2001) used the slope of demand curves as an indicator of market power. A concentrated market implied a steeply sloped consumer demand function. In Equation (1), we assume that the manufacturer's perceived customer demand is $Q=a X-b P$, with " $b$ " being the reciprocal of the demand curve's slope. Fig. 2 shows that a larger " $b$ " indicates a flatter demand curve and a lower intercept on the vertical price axis, suggesting that the manufacturer loses more customers from raising prices. Given any quantity, the price at $b=1.4$ is lower than that at $b=1.0$. A higher value of " $b$ " represents less market power, with $b \rightarrow \infty$ representing perfect competition (Taylor, 2000).

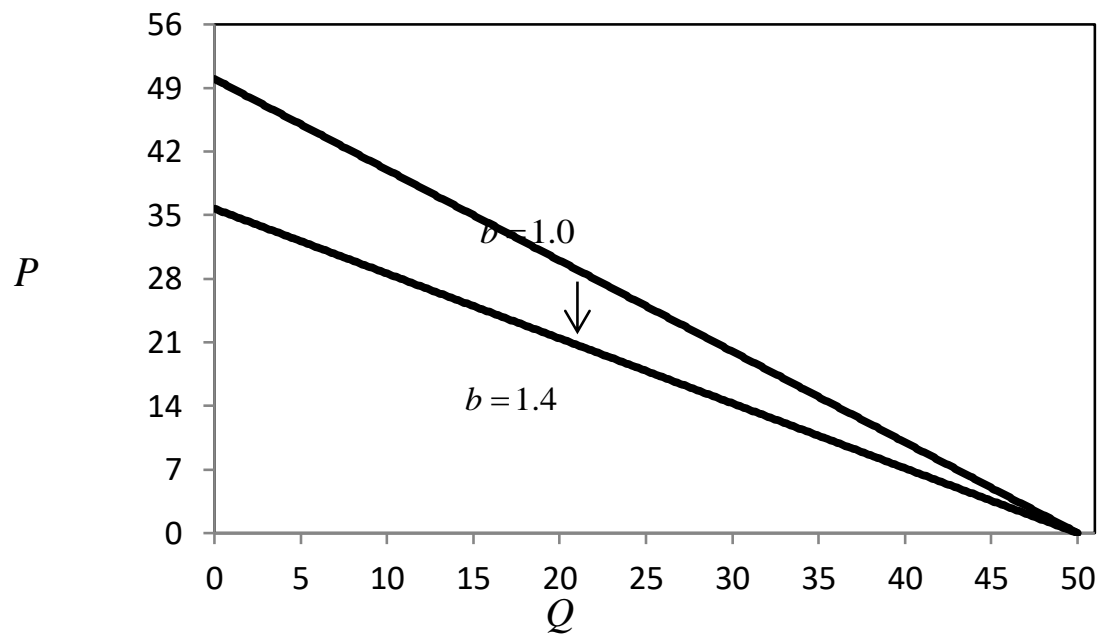

Figure 2: The demand curve, $Q=a X-b P, a=50$, becomes flatter as $b$ increases

Fig. 3 shows that a manufacturer with less market power tends to make smaller price changes in response to demand fluctuations. The price floor declines with the market-clearing prices but at a slower rate; as market power continues to weaken, the price become completely rigid. This is consistent with Taylor (2000), according to whom low market power would lead to a small price change in response to a change in demand. Caucutt et al. (1999) found that the sizes of price changes in consumer goods are positively related to market concentration. Domberger (1979) pointed that the costs of search and 
communication among sellers in concentrated industries are relatively low, price adjustments can be effectively coordinated, and equilibrium in the industry restored rapidly. Ball and Romer (1991) reasoned that with "coordination failure" or "competitiveness pressure," no company in competitive markets wants to be the first to change prices. It is dangerous for monetary authorities to target price levels as policy instruments (Kahn, 2009; Gaspar et al., 2010). For example, at point $A$, the central bank wants to use contractionary monetary policies to lower the price. However, it will not see the desired effect. The price remains the same even when demand has declined, because the prices are identical in the high and low-demand states. Therefore, the policymakers would further increase the magnitude of monetary policy. This might then be too strong and could harm manufacturers with low market power.

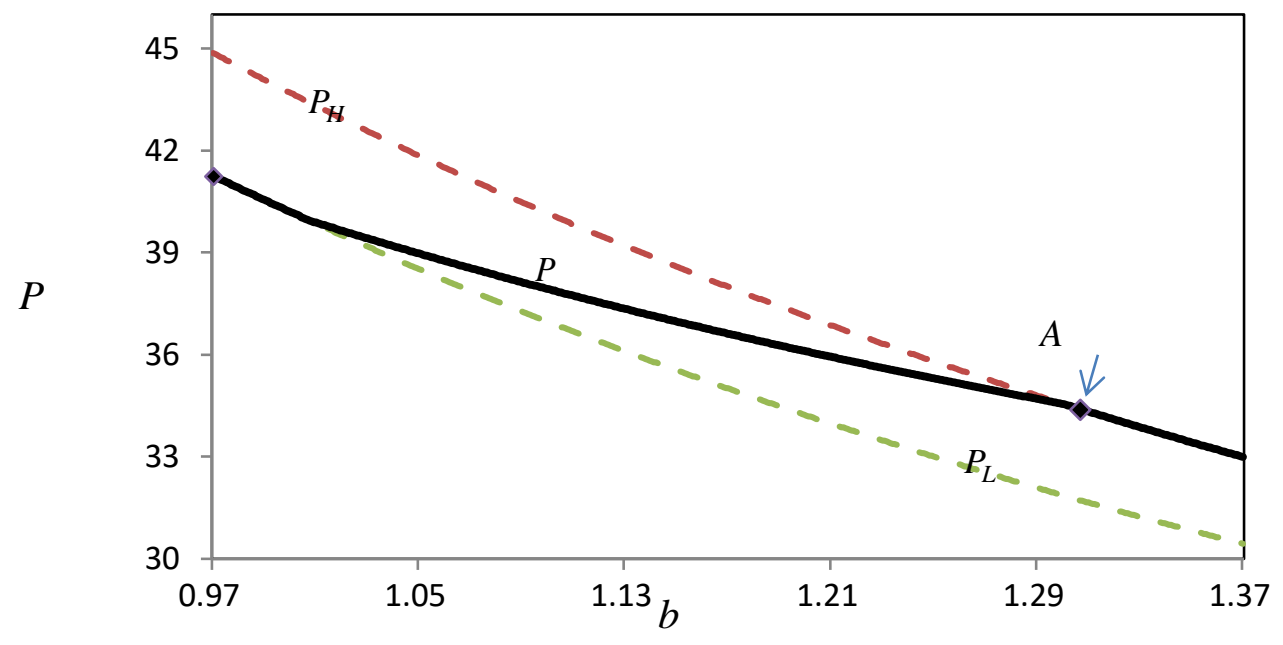

Figure 3: Market power of the manufacturer and price rigidity: without retailers.

Parameter values: $a=50, X=1, s=32, v=0.035, r=0.02, f_{0}=2, f_{1}=2$

Tables 1.1 and 1.2 compare the price rigidity model with the flexible pricing model with respect to the prices in the high and low-demand states, the standard deviation of price, the production output and the profits. The standard deviation of price, which is denoted by $S_{p}$, can be computed as:

$$
S_{p}=\sqrt{\alpha P_{H}^{2}+(1-\alpha) \operatorname{Max}\left(P_{L}, \underline{P}\right)^{2}-A V E_{P}}
$$

where $A V E_{P}=\alpha P_{H}+(1-\alpha) \operatorname{Max}\left(P_{L}, \underline{P}\right)$. The demand slope $b=0.95$ in Table 1.1 refers to a greater degree of market power than represented by $b=1.15$ in Table 1.2. Consistent with Fig.3, Tables 1.1 and 1.2 show that manufacturers with smaller market power adjust prices by smaller amounts in response to market demand changes. $S_{p}$ in the price rigidity model is lower than the corresponding value in the flexible pricing model when the manufacturer's market power is relatively small $(b=1.15)$. Table 1.2 also shows that $P_{H}$ in the price rigidity model is lower than its corresponding value in the flexible pricing model due to larger production quantities. The firm's profit $\pi_{M}$ in the price rigidity model is greater because choosing both a price floor and production output permits better use of the demand probability distribution relative to choosing production quantities alone. As product cost rises from $f_{0}=2$ to $f_{0}=10$, the price in the low demand state, $\operatorname{Max}\left(P_{L}, \underline{P}\right)$ in Table $1.1(b=0.95)$, increases by $\$ 1.39$, but $\operatorname{Max}\left(P_{L}, \underline{P}\right)$ in Table $1.2(b=1.15)$ does not change. This suggests that during economic recessions, the prices in competitive markets are less responsive to cost changes. These results correspond with those of Kraft (1995), who found that prices change more in economic recessions than in economic booms, and prices in more competitive industries adjusted less quickly to changes in costs or demand. In 
Table 1.2, as $f_{0}=10$ rises to $f_{0}=14, \operatorname{Max}\left(P_{L}, \underline{P}\right)$ increases by $\$ 0.50$; but if $f_{0}=10$ falls to $f_{0}=6, \operatorname{Max}\left(P_{L}, \underline{P}\right)$ does not fall accordingly. This asymmetry, which does not appear in Table 1.1, explains the results of Peltzman (2000) found that price transmission asymmetry is negatively related to market concentration. Peltzman (2000) concluded that asymmetric price transmission might be characteristic of competitive markets. This contradicts the traditional wisdom that market concentration and market power are the sources of price transmission asymmetry. Small manufacturers tend to choose prices based on expected market conditions and lack the ability to change it when market conditions vary. This is because lowering price in economic recessions does not help to generate much sales quantity to reduce the loss. So it is dangerous for antitrust policymakers to consider asymmetric price transmissions as evidence of high market concentration.

Table 1.1 The production cost and prices, $b=0.95$

\begin{tabular}{|c|c|c|c|c|c|c|c|c|}
\hline & \multicolumn{4}{|c|}{ price rigidity model } & \multicolumn{4}{|c|}{ flexible pricing model } \\
\hline$f_{0}$ & $P_{H}$ & $\operatorname{Max}\left(P_{L}, \underline{P}\right)$ & $S_{P}$ & $\pi_{M}$ & $P_{H}$ & $P_{L}$ & $S_{P}$ & $\pi_{M}$ \\
\hline 2 & 45.72 & 42.03 & 1.53 & 211.39 & 45.72 & 42.03 & 1.53 & 211.39 \\
\hline 6 & 46.41 & 42.73 & 1.53 & 179.31 & 46.41 & 42.73 & 1.53 & 179.31 \\
\hline 10 & 47.11 & 43.42 & 1.53 & 149.87 & 47.11 & 43.42 & 1.53 & 149.87 \\
\hline 14 & 47.80 & 44.11 & 1.53 & 123.06 & 47.80 & 44.11 & 1.53 & 123.06 \\
\hline
\end{tabular}

Table 1.2 The production cost and price, $b=1.15$

\begin{tabular}{|c|l|l|l|l|l|l|l|l|}
\hline & \multicolumn{4}{|c|}{ price rigidity model } & \multicolumn{4}{|c|}{ flexible pricing model } \\
\hline$f_{0}$ & $P_{H}$ & $\operatorname{Max}\left(P_{L}, \underline{P}\right)$ & $S_{P}$ & $\pi_{M}$ & $P_{H}$ & $P_{L}$ & $S_{P}$ & $\pi_{M}$ \\
\hline 2 & 38.61 & 36.99 & 0.67 & 151.26 & 38.70 & 35.66 & 1.26 & 150.79 \\
\hline 6 & 39.26 & 36.99 & 0.94 & 123.25 & 39.31 & 36.27 & 1.26 & 123.11 \\
\hline 10 & 39.92 & 36.99 & 1.21 & 98.24 & 39.92 & 36.88 & 1.26 & 98.23 \\
\hline 14 & 40.23 & 37.49 & 1.26 & 76.16 & 40.53 & 37.49 & 1.26 & 76.16 \\
\hline
\end{tabular}

Parameter values: $a=50, b=1, X=1, v=0.035, r=0.02, s=32, f_{1}=2$.

\section{Conclusions}

This study investigates the factors that influence price rigidity both with and without retailers. We make multiple contributions to the literature. First, market price volatility increases with the manufacturer's market power. Second, prices are more unresponsive to demand and cost shocks during economic recessions than in booms, due to the binding price floor, and this asymmetry might be a characteristic of competitive markets. The monetary policy might be too strong for small companies, and the reason underlying price rigidity should be considered while formulating monetary policy. Third, the retail price in a highly concentrated retail market might be lower than that in a retail market with fierce competition. The rigidity of retail prices increases with the degree of retail market competition. Fourth, price rigidity increases with the durability of the commodity. It is dangerous to use the rigid prices of durable goods as an indicator of strong demand.

If price rigidity is, as this model's prediction, more likely to take place in markets characterized with competition, macroeconomic policy might be too strong for companies with weaker market power. During the periods of contraction policy, since price floor coincide with high-demand prices, they cannot lower the prices to liquidate excess inventories during slack demand. If they choose to lower prices, the profits cannot be better than that under sticking with price floor. During contraction periods, small businesses can only choose either sticking price floor or closing business. 


\section{References}

Ball, L., \& Romer, D. (1991). Sticky Prices as Coordination Failure. The American Economic Review, 81(3), 539-552.

Bils, M., Klenow, P. J., \& Kryvtsov, O. (2003). Sticky prices and monetary policy shocks. Federal Reserve Bank of Minneapolis Quarterly Review, 27(1), 2-9.

Blinder, A., Canetti, E. R., Lebow, D. E., \& Rudd, J. B. (1998). Asking about prices: a new approach to understanding price stickiness. Russell Sage Foundation.

Caplin, A. S., \& Spulber, D. F. (1987). Menu costs and the neutrality of money. The Quarterly Journal of Economics, 102(4), 703-725.

Caucutt, E. M., Ghosh, M., \& Kelton, C. M. (1999). Durability versus concentration as an explanation for price inflexibility. Review of Industrial Organization, 14(1), 27-50.

Conlisk, J., Gerstner, E., \& Sobel, J. (1984). Cyclic pricing by a durable goods monopolist. The Quarterly Journal of Economics, 99(3), 489-505.

Cox, J. C., Ross, S. A., \& Rubinstein, M. (1979). Option pricing: A simplified approach. Journal of Financial Economics, 7(3), 229-263.

Dennis Carlton (1986) The rigidity of prices, American Economic Review, 76, 637-658.

Domberger, S. (1979) Price adjustment and market structure, Economic Journal, 89, 96-108.

Domberger, S. (1983) Industrial Structure, Pricing and Inflation, Martin Robinson, Oxford, UK.

Domowitz, I., Hubbard, R. G. and Petersen B. C. (1986) Business cycles and the relationship between concentration and price-cost margins, Rand Journal of Economics, 17, 1-17.

Gaspar, V., Smets, F. and Vestin D. (2010) Is the Time for Price-Level Path Stability?, in Siklos, Pierre, Bohl, Martin T. and Mark E. Wohar, Challenges in Central Banking: The Current Institutional Environment and Forces Affecting Monetary Policy, Cambridge University Press.

Holzer, P. S., \& Bittmann, T. (2019). Regular Price Stickiness in German Food Retailing. Journal of Agricultural \& Food Industrial Organization.

Kahn, G. A. (2009) Beyond inflation targeting: should Central Banks target the price level?, Federal Reserve Bank of Kansas City Economic Review, 2009, 35-64.

Klenow, P. J. and Kryvtsov O. (2008) State-dependent or time-dependent pricing: does it matter for recent U.S. inflation?, Quarterly Journal of Economics, 123, 863-904.

Kraft, K. (1995) Determinants of price adjustment, Applied Economics, 27, 501-507.

Mathews, K. H., Hahn, W., Nelson, K., Duewer, L. A. and Gustafson R. A. (1999) U.S. beef industry: cattle cycles, price spreads, and packer concentration, United States Department of Agriculture, Economic Research Service, Technical Bulletin No. 1874. April. Available at: http://www.ers.usda.gov/media/487899/tb1874_1_.pdf.

Meyer, J. and von Cramon-Taubadel S. (2004) Asymmetric price transmission: a survey, Journal of Agricultural Economics, 55, 581-611.

Nakamura, E. and Steinsson J. (2008) Five facts about prices: a reevaluation of menu cost models, Quarterly Journal of Economics, 123, 1415-1464.

Peltzman, S. (2000) Prices rise faster than they fall, Journal of Political Economy, 108, 466-502.

Rotemberg, J. J. and Saloner G. (1987) The relative rigidity of monopoly pricing, American Economic Review, 77, 917-926.

Serra, T., \& Goodwin, B. K. (2003). Price transmission and asymmetric adjustment in the Spanish dairy sector. Applied economics, 35(18), 1889-1899.

Taylor, J. B. (2000). Low inflation, pass-through, and the pricing power of firms. European economic review, 44(7), 1389-1408. 